\title{
Hunger and Thirst of Women for Accessing Higher Education in the 21 ${ }^{\text {st }}$ Century
}

\author{
Dr. Onoriode Collins Potokri \\ University of South Africa (Unisa), Dept. of Educational Leadership and Management \\ potokc@unisa.ac.za, cnuvie@gmail.com
}

\author{
Doi:10.5901/mjss.2014.v5n6p283
}

\begin{abstract}
The aim of this paper is to examine the reasons why women choose to access higher education in the twenty first century. It uses a feminist research lens, noting that women are newcomers to higher education, since it was only in the nineteenth and twentieth centuries that women began to access higher education, as a direct result of active feminist campaigning and their determination. Their determination is underscored by the reasons identified for their choice to access higher education. These include, among others, the need to develop their socialisation capabilities and their aspiration to be liberated from been tagged 'domestic engineers'. This paper, leaning on the gender-inclusive culture conceptual framework and extensive reviewed literature, also suggest that higher education has a direct impact on women's empowerment as it creates in them an awareness of their rights, their capabilities and the choices and opportunities available to them.
\end{abstract}

Keywords: women; higher education; access; gender-inclusive culture; feminist lens

\section{Introduction}

In this paper, hunger and thirst of women for accessing higher education connote reasons why women choose to access higher education. The position of women in higher education is an indicator of women's position in society at large. Kyomuhendo (2001:1), who directed his study on universities, notes "that women's role and progress in higher education can only be understood through an analysis of the sociology that situates the university in the society and defines it existence, goals and values". If higher education, by virtue of the important role it plays in the production of knowledge and research, is still to a large extent perpetuating gender bias, then there is a need to examine the systemic structures, norms and values of society that govern and define higher education and their ways of operating, which are significantly patriarchal (Endeley and Ngaling 2007). Despite studies (Bolarin 2001; 2006) pointing to low enrolment of women in higher education institutions, compared to their male counterparts, studies such as Aina, Oyetakin and Oshun (2009) and Kramarae (2001) note that the number of women accessing higher education is beginning to show improvement. While some of these studies give impeccable background to and analysis of the situation of women with regard to higher learning institutions, little was diagnosed or mentioned of the reasons why women in the 21st century choose to access higher education.

In this paper, I aim to examine the reasons why women choose to access higher education in the $21^{\text {st }}$ century. My examination is restricted to African women, specifically, black women, given their commonalities and history. In an attempt to meaningfully understand and as a yardstick for examining women's access to higher education, I locate my research lens within the feminist lens. I also considered different theoretical and conceptual frameworks aligned to the analysis of sociology as suggested for studies of this nature (Kyomuhendo 2001). In particular, a gender-inclusive culture was embraced.

\subsection{Background}

The role and progress of women in higher education can be understood via the goals and values of higher education, but is not limited to these goals and values, especially when the issue of their access to higher education is the main focus. Traditional constructions of the higher education student are rooted in longstanding conceptualisations of the individual in Western philosophy (Leathwood and Read 2009:95). Pateman (1988) demonstrated, based on the work of social contract theorists (Lock, Rousseau and others) on the founding of the liberal state, that only men were deemed to be individuals: "Only masculine beings are endowed with the attributes and capacities necessary to enter into contracts, the most important of which is ownership of property in person; only men, that is to say, are individuals" (Pateman 1988:5-6). Such "individuals" were assumed to be free and equal - and to inhabit the realm of reason, an arena from which women were 
excluded (Leathwood and Read 2009). On this premise, I suggest, lies the limitedness of higher education to men. Against this background, in 1998, emanated UNESCO's World declaration on higher education for the twenty-first century. Article 4 of the declaration states: "Enhancing participation and promoting the role of women is paramount to the 'ameliorative' decisions of women on higher education globally." For clarity's sake, though abridged, I reproduce article 4 below:

(a) Although significant progress has been achieved to enhance the access of women to higher education, various socio-economic, cultural and political obstacles continue in many places in the world to impede their full access and effective integration. To overcome them remains an urgent priority in the renewal process for ensuring an equitable and non-discriminatory system of higher education based on principle of merit.

(b) Further efforts are required to eliminate all gender stereotyping in higher education, to consider gender aspects in different disciplines and to consolidate women's participation at all levels in all disciplines, in which they are under-represented and, in particular, to enhance their active involvement in decision-making.

(c) Gender studies (women's studies) should be promoted as a field of knowledge, strategic for transformation of higher education and society.

(d) Effort should be made to eliminate political and social barriers whereby women are under-represented and in particular to enhance their active involvement in policy and decision-making level within higher education and society.

According to Leathwood and Read (2009: 29) it is telling that this declaration needed to be made at the end of the twentieth century to affirm the urgent need to address the participation and role of women in higher education, especially when one considers the time it took for women to gain access to higher education. Delamont (2006:179) remarked, "Women are newcomers to higher education." It was only in the nineteenth and twentieth centuries that women began to access higher education as a direct result of the determination and persistence of women, and of active feminist campaigning (Dyhouse 2006). The history of women's entry into higher education is not a simple, linear story of women "storming the citadel of higher education" to a wonderful state of equal opportunities for all (Dyhouse 1984:52). It comes with women's individual experiences.

In examining women's reasons for accessing higher education, the experiences of women that are in higher education should also be considered. It is in the light of this, that some of the findings of Potokri (2011) were embraced. In that study, the utilitarian value of education, the challenges and the opportunity cost, - in other words, the alternatives women had to forgo in order to enrol for higher education - as well as issues concerning their academic performance predominate. Little was made of the intrinsic value and the joy of learning, even though some participants claimed that their reason for enrolling in higher education is knowledge-oriented or motivated by knowledge acquisition. However, all women students (sampled participants) in the study (Potokri 2011), who were studying in higher education, aspired to become higher education graduates, because the acquisition of higher education qualifications or higher education certificates is needed for promotion in the workplace. This was especially true for those sampled participants who were working in corporate institutions. Some participants were also of the opinion that higher education will help them to be better mothers and wives (Potokri 2011; 2012), something which other women in the neighbourhood might want to emulate. With this in mind, they believe that it will have a positive impact on their children (Potokri 2011).

For some participants higher education was an ambition that they wanted to fulfil, while others viewed it a task that had to be accomplished in order for them to be relevant in the home (Potokri 2011; 2012). This was especially true for those participants who felt that their husbands looked down on them and would remark that they are illiterate because they do not have a higher education qualification (Potokri 2011; 2012). It is imperative to underline and acknowledge differences in women's background, appearance, educational levels, demographics, occupations and beliefs. As noted by Wood (2001), women may differ in all the aforementioned, but their reasons for choosing to study in higher education are similar. Collins (2001) highlights that their personal attributes may differ, but what connects them all is the struggle and aspiration to be accepted and respected members of society and a desire to have a voice that will be heard in a world where there are many views.

\subsection{Research lens/paradigm}

The focus of this paper is on the reasons why women choose to access higher education. In an attempt to ascertain my researching lens, I found parallels with the feminist lens (one among pragmatic paradigms), particularly in the domain of women's studies concerned with women's experiences and lives, how gender is constructed, and how and why gender roles are developed and perpetuated in terms of dominant culture and power issues (Potokri 2012). The feminist lens suggest a clear political motive that allows the researcher to raise the profile of gender and, more specifically, of women 
in the discourse around transformation (Shackleton 2007). As a means of raising the profile of women, I deem it necessary to take a look at the value of higher education for women, noting that higher education for them is essential and the number of women seeking to access it is on the increase (Kramarae 2001; Aina, Oyetakin and Oshun 2009). Knowing this was necessary yet not sufficient as the major reasons for their choice appears cloudy or variegated particularly in the $21^{\text {st }}$ century when women are seen as new comers to higher education. To concurrently understand while examining, I turn to the writings of Babbie (2008). Babbie (2008:40) notes that the "feminist lens not only reveal the treatment of women or the experience of oppression but often point to limitations in how other aspects of social life are examined and understood". That women choose to access higher education is an aspect of their social life that is worthy of been examined perhaps understood.

\section{Method}

In order to achieve the aim of this paper, I depended on the literature as my research instrument. Potokri (2014) notes, that literature are among the most imperishable possessions of humanity and knowledge of them is essentially necessary for research. Therefore, it is reasonable to agree with scholars like Cullum and Droogan (1999) that literature are powerful research tool or instrument researchers need in their business of researching. As Fouché and Delport (2005) indicate, a review of the literature is aimed at contributing towards a clearer understanding of the nature and meaning of the problem that has been identified. To be exact, a systematic review was sought. A systematic review attempts to identify, appraise and synthesize all the empirical evidence that meets pre-specified eligibility criteria to achieve research aims or answer a given research question (See Cochrane Handbook for Systematic Reviews of Interventions). I conducted a systematic search of the literature in peer reviewed academic journals with relatively high impact factor. These comprise classic and recent articles centred mainly on black women access to higher education before and at the entrance of the twenty first century. Also consulted, were other academic books, edited by reputable scholars and theses of proven and emerging researchers. Like the journals, books and theses focus directly and indirectly on women experiences and lives especially as its concerns their aspiration, persistence and determination to access higher education. Further to this, I was steadfast and conscious to align my readings with my philosophical assumptions research lens/ paradigm, that informs this research. This suggests that gender, women, access, higher education, feminist theory served as my keywords and search light. In agreement with Russell, Chung, Balk, Atkinson, Giovannucci, Stanley, Mayne, Raman, Ross, Trikalinos, West, and Lau (2009), I considered studies that employed both qualitative and quantitative research methods knowing that my feminist lens is located within the pragmatic paradigm. Although, and still adhered to notions of Russell et al. (2009), I excluded articles that are exclusively prescriptive or normative, as well as those lacking a basic comparative methodology. This was aimed at finding the most current and informative themes in terms of the reasons for women access to higher education.

When a literature review is conducted to provide a comprehensive understanding of what is 'assumed known' about a topic, the process is much longer. For example, Gadsden (2008) included almost two hundred (200) references in her review of arts education in order to examine the changing place of the arts in education through a lens of power, culture, and representation. Similarly, in this research, I consulted over one hundred (100) reference materials. It is typical that not all consulted literature would be referenced, except when the researcher chooses to use bibliography. Hence, only the cited references are shown in this paper. Russell et al. (2009), emphasis that the results of systematic review studies need to be synthesised and interpreted. In this paper, I synthesised and interpreted via discussion and conclusion respectively.

\section{Literature Review}

Several factors cause women to access or pursue higher education. The most common factors are the desire to broaden their knowledge and skills, to advance professionally and to build solid careers with the highest credentials (Wood 2001:108; Kramarae 2001). Other reasons for women's pursuit of higher education include: education as a tool for socialisation; education as a tool for liberation; the availability of funding/scholarships for women who want to advance their studies; the achievement of better post primary school results among women (Collins 2001); and less rigidity in religious and cultural practices (Okkolin, Lehtomaki and Bhalalusesa 2009). 


\subsection{Funding/Scholarships for women}

Funding is the act of setting aside or providing money for a specific programme or project. Funding is a function of financing that deals with the critical examination of the cost versus expenditure in the production of educational services. The real cost of an activity is not limited to the money spent on it, but the alternative opportunities that have to be foregone or sacrificed when a particular choice is made. Habermas (1987:171) argues that money is a major tool of system integration in advanced capitalist systems, where the majority of higher education institutions operate. Money may be experienced as a neutral artefact, but it carries immense real and symbolic power in system integration (Moss 2004). In this paper, funding is described as the money set aside as grants or scholarship by higher education institutions and paid to students directly or indirectly to finance their educational pursuits. Funding can be partial or total.

According to Moss (2004) in her work titled, 'Creating space for learning: conceptualizing women and higher education through space and time', the pressures on the whole household to accommodate the financial burden of a woman's higher education are complex given that the household had to decide who should bear the additional costs of higher education. Questions raised in her study include: What income can they afford to lose in order to create the space and time for the woman to access higher education? How can additional income be raised and who should raise it? Integral to this process is the need to justify higher education as a legitimate and socially valued burden on household resources. Moss (2004) found that for many households in her research, the answers to these questions were ambiguous and uncertain. Members of their households sometimes see women students as a risky investment.

Wood (2001), in a different study titled, Black Women in the academy, a research project conducted at Michigan University; disclosed good funding package/scholarship as a factor that can influence women's pursue of higher education. This finding is supported and confirmed by a woman student participant in Wood's research who said: "I came for the money and the reputation, because Michigan offered me the wonderful Rackham Fellowship. They basically offer you four years of funding. I thought to myself, getting paid to go to school, whoo-hoo!" ... (Wood 2001:109).

The funding package, as identified in Wood's work (2001), is what some other authors refer to as "funding equity access in higher education" (Clancy, Eggins, Goastellec, Gur-Rosenblit, Nguyen and Yizengaw 2007). Funding equity access concerns both the students (tuition fees, grants, scholarships and loans) and the institution. According to the aforementioned authors, three trends are evident in student funding:

(a) Although government remains the main providers, the financial burden on students continues to increase. This change is linked to a more widespread recognition that higher education is both a public and a private good and thus should involve cost-sharing;

(b) The degree of cost sharing is influenced by governance. The greater the level of autonomy of higher education institutions and the weaker the powers of public authorities, the greater the increase in tuition fees;

(c) Increasingly, centrally driven national/global frameworks are being developed to provide students with greater transparency with respect to tuition fees and funding possibilities. Also, the funding framework is becoming more complex to match equality of opportunity policies. Policies with respect to student funding, to improve equity in access, are increasingly being complemented by a focus on institutional funding (OECD 2006).

\subsection{Higher education as a tool of socialisation}

Socialisation is the process that prepares humans to function in social life. It should be noted that, socialisation is a key sociological process in the development of individuals who can function in human society. The concept of socialisation traditionally addresses the problem of individual adjustment to society. Socialisation has, in one way or another, referred to the idea that society shapes its members toward compliance and cooperation with societal requirement. Arnett (1995), in presenting a new theoretical understanding of socialisation outlined what he believes to be the three goals of socialisation: (a) impulse control and the development of a conscience; (b) role preparation and performance, including occupational roles, gender roles and roles in institutions such as marriage and parenthood; (c) the cultivation of sources of meaning or what is important, valued, and to be lived for.

In many patriarchal societies, "the purpose of education for all women, as determined by most analyses, has been socialisation" (Coleman-Burns 1989:145). In these societies, the woman's role is mainly confined to the domestic sphere, that is, confined to the home. This, to a large extent, cultivates a source of meaning, of what is important, valued and to be lived for by women as identified by Arnett (1995). As a means of living for what they value and consider important, women seek to access higher education, because it is a place for role preparation and performance which include the gender role assigned to them (Arnett 1995:12). Adequate role preparation and performance on the part of women is synonymous with the "cult of true womanhood" (Collins 2001:33). The "cult of true womanhood" focused on how a woman 
is judged by her husband, her neighbours and society; it is divided into four cardinal virtues: piety, purity, submissiveness and domesticity (Welter 1966:152). Jansen (2006:485) notes that in Jordan, the cultural prestige associated with higher education is a key issue which reflects positively on the family, father and husband: "It enhances her attractiveness and makes her worthy of a good partner." Jansen (2006) notes further that education has had the paradoxical effects of, on the one hand, teaching women an ideal of femininity based on domesticity, modesty and obedience while, on the other hand, encouraging them to take on a public role. She concludes that this has translated into an increase in the number of women accessing higher education.

\subsection{Higher education as a tool for liberation}

The purpose of higher education among many is to address issues of self-image and self-confidence of women and alter societal perception about them (Potokri 2012). Its overall goal is to create circumstances to enable women to better understand their predicament, to move from a state of abject disempowerment towards a situation in which they could determine their own lives and influence their environment and simultaneously create for themselves and their family an educational opportunity which will enhance the process of development (Singh, 2007).

Women's development is a pre-requisite for all-round development of the society. In a package of developmental inputs available to a community, education should form an effective means to improve the physical quality of life of the masses. Many studies have shown that there is a strong correlation between several developmental indicators and the level of literacy of the population, particularly with the level of women's education (Singh 2007).

Nielsen (2011), in Women of tomorrow study around the world, reveal that one vital way to a better life is through education. In developed economies, women's access to higher education is considered an established standard, while in emerging economies, attending college is often a luxury for women and the aspiration is much higher. Nielsen's study points to the need for women's empowerment as many of the participants mentioned it as one reason for allocating additional income for their children's education, particularly the female children. In his study, 56 percent of women in emerging countries say they plan to allocate additional income for their children's education. While these women acknowledge the importance of education for their children as the "next generation", whom they want to see contribute meaningful to their societies, they were equally aware of the need to be educated themselves. Women in Nigeria, India and Malaysia placed the most importance on the need to save for their children's education - a choice that ranked in the top three out of 25 different options for how they plan to allocate their additional salary in the next five years (Nielsen 2011:12). Some of the reasons given for their choice include their awareness of the usefulness of education for women and men alike.

Quinn's (2003) research into black women in higher education in England identified higher education as a space that provides refuge and freedom for women. This, according to Quinn (2003), raises a question about the ways in which higher education may both challenge and reinforce traditional gender relations. Many black women now see higher education accessibility or participation as a way of changing their lives, providing new opportunities for their future and their children and increasing their financial independence (Leatherwood and Read 2009:41). In Uganda, for example, women see higher education as an important route out of poverty, whilst also providing them with an opportunity to be engaged in the development of their country (Kwesiga 2002).

\subsection{Safety and inclusive environment}

It has been noted that the provision of a safe and inclusive environment is the responsibility of the universities in order to allow everyone to achieve their potential (FAWE 1998). This supports the agitation of the UNDP Gender Equality Strategy 2008-2011 (2008) that women must live without the fear of coercion and violence. Living without fear of coercion and violence is an important indicator of a gender- inclusive culture: the conceptual framework that informs this paper. Establishing, regulating and governing the rights of women and men, in relation to sexual harassment and exploitation in most higher education institutions could help to promote women's access to such institutions. Corroborating this is Potokri's (2011) research about higher education in Nigeria, conducted at the University of Pretoria, South Africa. Through his research, he notes that the husbands of married women students studying at universities and colleges of education are concerned about sexual harassment and exploitation of their wives and, therefore, tend to withhold support for higher education for their wives, especially when cultural practice sensitivity concerning marriage in the country is considered.

In recent times, higher education institutions have frowned on and punished perpetrators of sexual harassment and similar crimes. According to Endeley and Ngaling (2007), culprits, especially students, are dismissed and such acts 
reported to the police or they are suspended from studies ranging from one semester to one academic year, depending on the gravity of the case. While the punishment for students is well-defined, the punishment of major actors in female students exploitation and harassment, that is, the teaching staff, is not (Endeley and Ngaling 2007). The action of Professor Leigh Abisogun, former Vice-Chancellor of the Lagos State University, Nigeria against an assistant lecturer in the department of English and linguistics for sexual harassment and exploitation of a female student was applauded by the university community and the larger society (Dike 2005). The concerned lecturer was arrested by the police and the university also dismissed the lecturer (Dike 2005). Even if no research has referred to this, at least none that I know of, I am confident that the action of the Vice-Chancellor would have made some impact on the hopes and confidence of current and prospective female students studying at that university.

\subsection{Establishing gender and women studies departments}

Women's studies is not a single entity, rather it is a multidisciplinary approach to teaching, research and knowledge (Marchbank and Letherby 2006). As Humm (1989:301) summarises, women's studies "is the study of power and gender relationships and it uses educational techniques of cooperation and consciousness raising to enable women to learn together as women". This aspect (as distinct from conventional or "traditional" approaches) has been well-documented (Aaron and Walby 1991). Women's studies classes may specifically address literature, geography, politics and/or economics, however, all these subject fields share an approach that argues that a systematic consideration of gender provides the basis of understanding society (Marchbank and Letherby 2006). As such, women's studies do not add gender to existing academic areas and debates, but it has rather challenged and changed the content of academic courses as a result of the recognition that all existing knowledge and knowledge creation are influenced by the unequal distribution of social power between women and men (Evans 1983). For instance, the works of Endeley and Ardener (2004) on the impact of a Department of Women and Gender Studies in higher education, at the University of Buea in Cameroon, reveal that the department of women and gender studies in higher education promote government endorsement of gender equality and women's advancement in society.

\section{Conceptual Framework: Gender- Inclusive Culture}

A gender-inclusive culture, takes into account feminist critiques and gender analysis. Gender-inclusive culture implies, more or less, a public recognition that innumerable obstacles and challenges exist and need to be tackled (UNESCO 1998b). Feminist pedagogy foregrounds gender-inclusive culture. Referring to gender- inclusive culture, Jackson (1997:466) notes that "an educational theory or concept which fails to take into account feminist critiques and gender analysis in a study synonymous to this paper is doing disservice to both men and women by not considering the ways in which existing pedagogies can be enriched".

Jackson, being a woman, stresses the need to engender education. In the course of buttressing her argument, she makes reference to the views of Welch (1994), Weiner (1994) and Welch (2000), who posit that feminist pedagogy is based on three principles: to strive for egalitarian relationships in the classroom; to try to make all students feel valued as individuals; and to use the experience of students as a learning resource in order to bring about social transformation. These principles serve as a genesis as well as an exodus to a robust concept, that is, a gender- inclusive culture that includes more principles, also known as indicators, aimed at a better understanding of the role of women and promoting social transformation of women.

Education is an agent for transformation; therefore, accessing it is a vehicle or enhancer. There are nine important indicators for the existence of a gender-inclusive culture (see table 1). Analysis of the indicators, in Endeley and Ngaling's (2007) study entitled, Challenging gender inequality in higher education: attitudes and perceptions of teaching staff and administrators at the University of Buea, Cameroon, led to the underlying principles that foster the framework for this paper. These principles are empowerment, co-operation, equity, sustainability and security as shown in the table below. 
Table 1: Summary of gender- inclusive culture: principles and indicators

\begin{tabular}{|l|l|}
\hline $\begin{array}{c}\text { Principle for fostering a gender- } \\
\text { inclusive culture }\end{array}$ & \multicolumn{1}{c|}{ Gender-inclusive indicators } \\
\hline Empowerment & $\begin{array}{l}\text { - Support for interventions that reduce female students and women's labour in order that } \\
\text { more time can be invested in academic work }\end{array}$ \\
& $\begin{array}{l}\text { - Support for a gender perspective being considered in research in academic work } \\
\text { - Support for appropriate targets, indicators, time frames and monitoring and evaluation } \\
\text { strategies that are sensitive to promoting the advancement of women. }\end{array}$ \\
\hline Co-operation & $\begin{array}{l}\text { Support for women and men sharing household management and child-rearing duties in } \\
\text { order for women to have enough time to pursue academic careers. }\end{array}$ \\
\hline Equity & $\begin{array}{l}\text { - Support for the use of gender-sensitive language in all oral and written communication, for } \\
\text { example, he/she, chairperson instead of chairman, etc. }\end{array}$ \\
\hline Sustainability & $\begin{array}{l}\text { Advocacy for pedagogy training in order to mainstream gender in all the courses in the } \\
\text { existing faculties and schools in higher education. }\end{array}$ \\
\hline Security & $\begin{array}{l}\text { Advocacy for the state to provide grants and other resources to support men and women } \\
\text { who opt to pursue academic careers. }\end{array}$ \\
\hline $\begin{array}{l}\text { - Encouraging the punishment of persons guilty of sexual harassment. } \\
\text { - Encouraging research on the level of sexual harassment on campuses, its impact on both } \\
\text { men and women and how it can be redressed. }\end{array}$ \\
\hline
\end{tabular}

Source: Endeley and Ngaling (2007:68)

\section{Discussion}

Higher education in the past was perceived as men's institutions, that is, exclusively for men, implying a dominant culture (Potokri 2011; 2012). This explains why women have only recently been able to access higher education. From the literature, it is inferred that specific reasons derived from the body of literature on women's access to higher education informs our present understanding and realities about the reasons why women choose to access higher education, particularly in recent years (Delamont 2006). Specific mention or reference was not made of the different categories of women, therefore it is assumed that the literature generalised women as an entity irrespective of their age, background and health-related issues. The literature illuminate that the reasons for women choosing to access higher education include, but is not limited to the availability of funds for women to study at a higher education institution; the introduction of enhanced safety measures and the creation of an inclusive learning environment for women at higher learning institutions as well as the establishment of gender and women studies department at institutions of higher learning. The literature also reveal that women want to develop their socialisation capabilities and they aspire to be liberated from the tag 'domestic engineers', that is, they do not want be confined to the home, but want to be useful to society at large and by completing a higher education qualification they can get employment outside the home and, in this way, contribute to society.

Common to the literature reviewed and the conceptual framework; are the three principles of gender-inclusive indicators Welch (1994), Weiner (1994) and Welch (2000) emphasise, these are: equity, safety and inclusive environment, women and gender studies. By and large, these are the major reasons why women access higher education. The aforementioned reasons link to the importance of creating egalitarian relationships in classroom; to try to make all students feel valued as individuals; and to use the experience of students as a learning resource in order to bring about social transformation respectively (Weiner 1994; Welch 1994; 2000).

The above touch on support for the use of gender-sensitive language in all oral and written communication, for example he/she, chairperson instead of chairman, encouraging the punishment of persons guilty of sexual harassment, encouraging research on the levels of sexual harassment on campuses, its impact on both men and women and how it can be redressed (Endeley and Ngaling 2007:68), and using the domestic experience of women students as a learning resource in order to make learning interesting, meaningful and relevant to their everyday life. Equity as a key reason for higher education access is connected to funding. This implies that to achieve equity, funding is required. Clancy, Eggins, Goastellec, Gur-Rosenblit, Nguyen and Yizengaw (2007) note that funding equity in access concerns both the students (tuition fees, grants, scholarships, and loans) and the institution. Based on this, it is therefore imperative to include funding, as identified in the literature, as a key reason why for women choose to access higher education because it carries immense real and symbolic power (Moss 2004). 
Education of women is vital, not only to liberate women from tradition roles, but also because it accelerates social transformation and promoted gender equality. Promotion of gender equality in education is essential for human resource development. By educating a woman you educate the whole family; given that a woman is a basic unit of the family, and the responsibility of taking care of the whole family is mostly on her. Therefore, an educated woman is better capable of taking care of the health, nutrition and education of her children and she should, therefore, be regarded as an active agent in the social and economic development of the country. It is evident in this paper that higher education for women is a facilitator to their ambitions and aspirations, especially when viewed from their career development stance. This suggests that socio-economic development should be based on access to education for women and the success of women. Therefore, higher education for women can be regarded as a requirement for a progressive society. It leads to an improvement in the depth and quality of public opinion as a result of more active participation of the women in societal and developmental issues. No society has ever liberated itself economically, politically or socially without a sound base of educated women (for example, the Aba Women's Riot of 1929, in Nigeria and the historic Women's March to Pretoria, 9 August 1956, in South Africa, etc.).

\section{Conclusion}

This paper illuminates that equity; safety and an inclusive environment; women and gender studies departments in institutions of higher learning and funding are the key factors that promote hunger and thirst of women for accessing higher education in the $21^{\text {st }}$ century.

Higher education has a direct impact on women's empowerment as it creates in them awareness about their rights, their capabilities and the choices and opportunities available to them. This alone is powerful enough for women to opt for or access higher education. The conceptualisation that frames this research concurs with the reviewed literature as they both suggest that there is a strong correlation between women's education and several developmental indicators such as empowerment, co-operation, equity, sustainability and security. With these indicators, increased economic productivity is envisaged and possibly enhanced. This suggests further that society must include women in every sphere of life including higher education if disservice to both men and women is to be avoided as Jackson (1997) noted. To achieve this, drawing on assertions of UNESCO (1998b), I affirm that innumerable obstacles and challenges exist and, as such, these need to be continuously tackled.

\section{References}

Aaron, J \& Walby, S. 1991. Out of the margins: women's studies in the nineties. Basingstoke: Falmer.

Aina, S., Oyetakin, A I \& Oshun, G O. 2009. Impact of economic depression on the education of male and female undergraduates in Nigeria. Medwell Journals of the Social Sciences 4(6):610-613.

Arnett, J J. 1995. Broad and narrow socialization: the family in the context of a cultural theory. Journal of marriage and the family 57(3):617-28

Babbie, E. 2008. The basics of social research. 4th edition. Thomson Wadsworth. USA

Bolarin, T A. 2001. Female educational enrolment in Nigeria: a psycho-social perspectives. Pedagogue 1(1).

Bolarin, T A. 2006. Female education in a depressed Nigerian economy: the way forward. First edition. Inaugural Lecture, Educational Technology Centre, Lagos State University

Bucker, H. 2000. Namibian Women's Movement, 1980 to 1992: From Anti-Colonial Resistance to Reconstruction. Frankfurt: IKO

Clancy, P., Eggins, H., Goastellec, G., Guri-Rosenblit, S., Nguyen, P N., \& Yizengaw, T. 2007. Comparative perspectives on access and equity, in Higher education in the new century: global challenges and innovative ideas. Edited by PG Altbach and Patti McGill. Rotterdam, the Netherlands: Sense Publishers: 35 - 54.

Coleman-Burns, P. 1989. African-American women - education for what? Sex Roles 21(5): 145-160.

Collins, A C. 2001. Black women in the academy: an historical overview, in Sisters of the Academy: Emergent Black Women scholars in higher education by AL Green and edited by R Mabokela. Stylus Publishing LLC

Cullum, N \& Droogan, J. 1999. Using research and the role of systematic reviews of the literature. In: Mulhall A. Le May A. eds. Nursing Research: Dissemination and Implementation. Churchill Livingstone, Edinburgh: 109-123

Delamont, S. 2006. Gender and Higher Education, in Sage handbook of gender and education edited by C Skelton, B Francis and L Smulyan. London: Sage.

Dike, G. 2005. Lasu fires Oriola: sex-for-marks lecturer. Available http://nm.onlinenigeria.com/templates/?a=4395\&z=12. (Accessed 2 November 2013).

Dyhouse, C. 1984. Storming the citadel or storm in a teacup? The entry of women into higher education 1860-1920, in Is Higher Education Fair to Women? edited by S Acker and DW Piper. Guildford: SRHE and NFER-Nelson.

Dyhouse, C. 2006. Students: a gendered history. London: Routledge.

Endeley, J M \& Ardener, S. 2004. Gender-inclusive culture in higher education: the case of the University of Buea, in New Gender 
Studies from Cameroon and the Caribbean edited by J Endeley, s Ardener, R Goodridge and N Lyonga. Cameroon: Department of Women and Gender Studies, University of Buea.

Endeley, J M \& Ngaling, M N. 2007. Challenging gender inequality in higher education: attitudes and perceptions of teaching staff and administrators at the University of Buea, Cameroon. Feminist Africa. Rethinking Universities 11:63- 84

Evans-Pritchard, E. E. 1983. Witchcraft, oracles and magic among the Azande. Abridged edition. Oxford

FAWE. 1998. Creating an enabling and empowering environment for women in tertiary education: a handbook for African universities. Nairobi: FAWE

Fouché, C B \& Delport, C S L. 2005. In-depth review of literature. In De Vos, H. Strydom, C. B Fouche \& CSL Delport (eds). Grassroots research for social sciences and human service professions. 3rd edition Pretoria:Van Schaik

Gadsden, V L. 2008. The arts and education: Knowledge generation, pedagogy, and the discourse of learning. Review of research in education, 32, 29-61.

Habermas, J. 1987. Volume two life world and system: the theory of communicative action. The critique of functionalist reason.Cambridge:Polity.

Higgins JPT, G S. (editors). Cochrane Handbook for Systematic Reviews of Interventions Version 5.1.0 [updated March 2011]. The Cochrane Collaboration, 2011. www.cochrane-handbook.org. (Accessed 14 July 2013)

Humm, M. 1989. The dictionary of feminist theory. Hemel Hemstead, UK: Harvester Wheatsheaf.

Institute for Women and Gender Studies. 2004. Annual Report. University of Pretoria, Pretoria.

Jackson, S. 1997. Crossing borders and changing pedagogies: from Giroux and Freire to feminist theories of education. Gender and Education 9(4):457-468

Jansen, W. 2006. Gender and the expansion of university education in Jordan. Gender and Education 18(5):473-490

Kramarae, C. 2001. The third shift: women learning online. Washington, DC: American Association of University Women Educational Foundation

Kwesiga, J C. 2002. Women's access to higher education in Africa: Uganda's experience. Kampala, Fountain Publishers.

Kyomuhendo, B G. 2001. Women in academia: voices from the south. Uganda: Makerere University. www.unit.no/semut/rapportedoks/url-NUFU-Gender/pdf-kapotler/9751Batebya.pdf (Accessed 4 September 2012).

Leathwood, C \& Read, B. 2009. Gender and the changing face of higher education: a feminised future? The society for research into higher education: Berkshire, England: Open University.

Marchbank, J \& Letherby, G. 2006: Views and perspectives of women's studies: a survey of women and men students. Gender and Education 18(2):157-182

Moss, D. 2004. Creating space for learning: conceptualizing women and higher education through space and time. Gender and Education 16(3):283-302.

National Universities Commission. 2002. Annual Report. Abuja: NUC

Nielsen 2011. Reports and insights: women of tomorrow: a study of women around the world http://se.nielsen.com/site/documents WomenofTomorrowwhitepaperFINAL062611.pdf (Accessed 14 November 2012)

Okkolin, M., Lehtomaki, E \& Bhalalusesa, E. 2009. The successful education sector development in Tanzania - comments on gender balance and inclusive education. Gender and Education 22(1):63-71. www.Tandonline.com/loi/cgee20 (Accessed 21 July 2011).

Pateman, C. 1988. The Sexual Contract. Cambridge: Polity.

Potokri, O C. 2011. The academic performance of married women students in Nigerian higher education. PhD thesis. University of Pretoria, South Africa.

Potokri, O C. 2012. Experience of women in higher education: women and higher education: Nigerian perspective. Colne, German: Lambert Academic.

Potokri, O C. 2014. Conversations with epistemologies of feminism: a systematic review. Mediterranean Journal of Social Sciences. Vol. 5 (1). Forthcoming

OECD. 2006. Annual report. http://www.oecd-ilibrary.org/docserver/download/0106071e.pdf?expires=1383222251\&id=id\&accname =guest\&checksum=BF3AFABD5C88337F6D9930FBD3DA6672 (Accessed 10 October 2012).

Quinn, J. 2003. Powerful subjects: are women really taking over the university? Stoke on Trent, UK: Trentham.

Quinn, J. 2004. The corporeality of learning: women students and the body, in The politics of gender and education: critical perspectives edited by S Ali, S Benjamin and M Mauthner. London: Palgrave Macmillian.

Russell, R., Chung, M., Balk, E M., Atkinson, S., Giovannucci, E L., Stanley I P., Mayne, S T., Raman, G., Ross, C A., Trikalinos T., West, K P., \& Lau, J. 2009. Issues and Challenges in Conducting Systematic Reviews to Support Development of Nutrient Reference Values: Workshop Summary. Nutrition Research Series, Vol. 2. Technical Reviews, No. 17.2

Shackleton, L. 2007. Lost in liberalism: a case study of the disappearance of the gender agenda at a South African University. Feminist Africa. Rethinking Universities 11(9): 26-27.

Singh, Y K. 2007. Sociological foundation of education. New Delhi: APH Publishing.

UNDP. 2008. Empowered and equal: gender equality strategy 2008-2011. New York: USA: Bureau for Development.

UNESCO. 1998a. Thematic debate: women and higher education: issues and perspectives. Paris: Unesco

UNESCO. 1998b. Women and management in higher education: a good practice handbook. URL: http://www.unesco.org/education /pdf/singh.pdf (Accessed 16 December 2010).

Weiner, G. 1994. Feminisms and education: an introduction. Buckingham: Open University.

Welch, P. 2000. "Feminist pedagogy and power in the academy", workshop facilitated at the Feminist Pedagogy Conference, hosted by 
the Institute for Feminist Theory and Research, Liverpool University.

Welter, B. 1966. The Cult of True Womanhood: 1820-1860. American Quarterly 18(2):151-174

Woods, R L. 2001. The invisible women: the experiences of black female doctoral students at the University of Michigan, in Sisters of the Academy: emergent black women scholars in higher education by AL Green and edited by R Mabokela. Stylus Publishing LLC. 